\title{
Azo dye decolorization in an up-flow bioelectrochemical reactor with domestic wastewater as a cost-effective yet highly efficient electron donor source
}

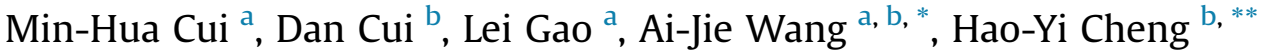 \\ a State Key Laboratory of Urban Water Resource and Environment, Harbin Institute of Technology, Harbin 150090, PR China \\ ${ }^{\mathrm{b}}$ Key Laboratory of Environmental Biotechnology, Research Center for Eco-Environmental Sciences, Chinese Academy of Sciences, Beijing 100085, PR China
}

\section{A R T I C L E I N F O}

\section{Article history:}

Received 11 July 2016

Received in revised form

11 September 2016

Accepted 18 September 2016

Available online 19 September 2016

\section{Keywords:}

Bioelectrochemical system

Domestic wastewater

Azo dye

Electron donor source

Cost-effective

\begin{abstract}
A B S T R A C T
A major challenge of employing bioelectrochemical system (BES) for reductively degrading recalcitrant contaminants in industrial wastewater is lacking sufficient electron donors. In this work, domestic wastewater (DW) was demonstrated to efficiently drive BES for implementing the decolorization of azo dye, acid orange 7 (AO7). Side benefit was the simultaneous treatment of DW. Decolorization efficiency in BES fed with DW ( $R_{D W}$ ) was found to be comparable with that either fed with glucose ( $\left.R_{G l u}\right)$ or acetate $\left(R_{A C}\right)$. Much lower reductant usage ratio was observed in $R_{D W}$. As a result, when the ratio of electron donors to azo dye decreased to $4.4 \mathrm{~mol} \mathrm{COD} \mathrm{mol}^{-1}$ AO7, DE of $\mathrm{R}_{\mathrm{DW}}$ kept over $90 \%$ while DEs of $\mathrm{R}_{\mathrm{Ac}}$ and $\mathrm{R}_{\mathrm{Glu}}$ were significantly dropped due to the insufficient electrons donation. Besides serving as electron donor, DW was proved to also provide some conductivity and buffer capacity. Accordingly, $\mathrm{DE}$ of $\mathrm{R}_{\mathrm{DW}} \mathrm{Was}$ less deteriorated when fully removing the external buffer slats. This study comprehensively revealed the feasibility and superiority of DW as a cost-effective electron donor source in BES and brings this technology closer to the practice.
\end{abstract}

๑ 2016 Elsevier Ltd. All rights reserved.

\section{Introduction}

Bioelectrochemical systems (BESs) have been suggested to be a promising technology in reductive degradation or transformation of diverse contaminants, including nitroaromatics (Mu et al., 2009b; Wang et al., 2011), azo dyes (Cui et al., 2016a, 2016c), halogenated compound (Kong et al., 2015; Liang et al., 2013), heavy metals (Huang et al., 2014; Luo et al., 2014), nitrate (Pous et al., 2014), etc. Although superior performance of BES compared to the traditional biological processes were extensively reported in these contaminants, this technology is still far away from the practice as most of the existed studies were performed at lab scale and under ideal conditions, such as strong buffered system, sufficient electron donors and excellent conductivity.

Azo dyes are one group of the most concerned contaminants in

\footnotetext{
* Corresponding author. State Key Laboratory of Urban Water Resource and Environment, Harbin Institute of Technology (SKLUWRE, HIT), P.O. Box 2614, 202 Haihe Road, Harbin 150090, PR China.

** Corresponding author.

E-mail addresses: waj0578@hit.edu.cn (A.-J. Wang), hycheng@rcees.ac.cn (H.-Y. Cheng).
}

refractory wastewater treatment, because they account for more than half of the used dyestuffs in the textile industry which is highly water consuming (Cui et al., 2016b). Due to the low utilization efficiency, about 2-50\% of these dyestuffs are unemployed and exist in the effluent (Ganesh et al., 1994), which is harmful attributed to the apparent color and the toxicity to the organisms (Selvam et al., 2003). The decolorization of azo dyes is a reductive process involved in four electrons transfer for breaking one azo bound $(-\mathrm{N}=\mathrm{N}-$ ). In BESs, electron donors (organic carbon) are oxidized by anode respiration bacteria (ARB) with electrons transfer to the anode and further going to the cathode for implementing the decolorization (Mu et al., 2009a). To date, a number of electron donors, including acetate, glucose, yeast extract, etc., have been demonstrated to drive the cathodic decolorization (CardenasRobles et al., 2013; Cui et al., 2014a, 2016a). However, these chemicals were external supplied, which could therefore cause the extra cost in operation. Compared to the addition of chemicals, using waste streams as electron donor source is obviously more cost effective and may gain the benefit of treating the waste streams simultaneously. Various kinds of waste streams (e.g. lignocellulose (Gregoire and Becker, 2012), digestate (Wang et al., 2014) and domestic wastewater), have been reported as the 


\begin{tabular}{|llll|}
\hline \multicolumn{2}{|c|}{ Abbreviations } & $\mathrm{NaCl}$ & Sodium chloride \\
& & $\mathrm{PBS}$ & Phosphate buffer solution \\
AN & 1-amino-2-naphthol & $\mathrm{R}_{\mathrm{Ac}}$ & BES fed with acetate \\
AO7 & Acid orange 7 & $\mathrm{R}_{\mathrm{DW}}$ & BES fed with DW \\
ARB & Anode respiration bacteria & $\mathrm{R}_{\mathrm{Glu}}$ & BES fed with glucose \\
BES & Bioelectrochemical system & RSR & Reductant supply ratio \\
COD & Chemical oxygen demand & RUR & Reductant usage ratio \\
DE & Decolorization efficiency & SA & Sulfanilic acid \\
DR & Decolorization rate & SCE & Saturated calomel electrode \\
DW & Domestic wastewater & SS & Suspended solids \\
FID & Flame ionization detector & TCD & Thermal conductivity detector \\
HRT & Hydraulic retention time & VSS & Volatile suspended solids \\
NaAc & Sodium acetate & & \\
& & & \\
\hline
\end{tabular}

efficient substrates for ARB in other types of BESs, such as microbial fuel cell for electricity generation and microbial electrolysis cell for hydrogen production (Heidrich et al., 2014; Kim et al., 2015). In case of driving azo dyes decolorization, domestic wastewater (DW) seems more adaptable because it is readily accessed. In addition, most of the textile factories were located close to cities or towns and their discharged wastewater is usually treated together with DW (Chen et al., 2011). Thus, to understand the performance of DW as electron donor source for decolorization in BESs is crucial in regard to practicing this technology.

Up to now, DW as electron donor source for azo dye decolorization in BESs has not been systemically studied. Although the feasibility of DW as electron donor source has been reported (Kim et al., 2015), the performance was not compared with other extensively used electron donors under identical conditions and consequently a fair evaluation of the efficiency is difficult. Additionally, unlike the solid organics as electron donor, DW would dilute the original azo dye containing wastewater. The decrease of conductivity and buffer capacity may influence the decolorization efficiency. This issue is also worth to be clarified before DW is capable of serving as an eligible electron donor source in BESs.

According to the concerns as above, here, the decolorization performance with DW as the electron donor source in BES was systemically investigated. Conventional external carbon sources, acetate and glucose, were employed as comparisons. The effects of azo dye loading rate, electron donor concentration and the external buffer salts on decolorization efficiencies were studied under these three different electron donor source conditions. The perspective of using DW as electron donor source for driving BES in practice was discussed as well.

\section{Material and methods}

\subsection{Reactor configuration}

Three identical cylindrical reactors were manufactured with plexiglass (schematic representation of the reactors were shown in Supporting Information (SI), Fig. S1). Each one had a working volume approximately $1.25 \mathrm{~L}$ with the inner diameter of $8 \mathrm{~cm}$ and a height of $25 \mathrm{~cm}$. Two pairs of electrodes were installed into the reactor, from the bottom to the top, which were arranged as downcathode, down-anode, up-cathode and up-anode with the distance of $2.5 \mathrm{~cm}$ between each electrode. Both anodes and cathodes were constructed by granular graphite (diameter from 3 to $6 \mathrm{~mm}$, Linzhang county Deyuan carbon co., LTD, Handan China) with an apparent size of $8 \mathrm{~cm}$ in diameter and $4 \mathrm{~cm}$ in height, giving the total electrode volume of $200 \mathrm{~cm}^{3}$. Before using, the granular graphite was washed by soaking in $32 \% \mathrm{HCl}$ for four times to remove the foreign materials (Mu et al., 2009a). Graphite rod $(\Phi=4 \mathrm{~mm})$ penetrated into the electrode zone and worked as an electron collector. A saturated calomel electrode (SCE, $+247 \mathrm{mV}$ vs. standard hydrogen electrode, model-217, Shanghai Precise Sci. Instru. Co., Ltd. China) was used as the reference electrode. During all of the experiments, voltage of $0.5 \mathrm{~V}$ was supplied between anode and cathode by a DC power supply (FDPS-180, Fudan Tianxin Scientific and Educational Instruments Co., Ltd, Shanghai, China). A $10 \Omega$ resistor was connected in series into the electric circuit. The voltages cross this resistor were recorded every $10 \mathrm{~min}$ by a data acquisition system (Keithley 2700, Keithley Co. Ltd., U.S.), which were automatically converted to current according to Ohm law.

\subsection{Chemicals}

Acid orange 7 (AO7) was used as the model azo dye (purity $>95 \%$, Shanghai Sangon Biotech Co., Ltd., China). The products of AO7 reduction were sulfanilic acid (SA) and 1-amino-2-naphthol (AN) (Mu et al., 2009a). In this study, SA (primary reagent, Aladdin Industrial Corporation) was used to calculate the product formation efficiency. All other chemicals were analytical reagent.

\subsection{Startup and operational conditions}

All of the three reactors were startup in batch mode. Effluent that collected from a long-term operated single chamber BES was amended with sodium acetate (NaAc, $1000 \mathrm{mg} \mathrm{l}^{-1}$ ) and AO7 (200 $\mathrm{mg} \mathrm{l}^{-1}$ ) as the inoculum solution. In the first batch operation cycle, $50 \mathrm{~mL}$ anaerobic activated sludge (SS of $35.57 \mathrm{~g} \mathrm{l}^{-1}$ and VSS of $17.11 \mathrm{~g} \mathrm{l}^{-1}$ ) was also added into the reactors to strengthen the biomass. After that, the inoculum solution was replaced every two days. When a stable current output was observed, the reactors were considered to be successfully started up.

Subsequently, the operation of reactors was changed to continuous flow mode. Domestic wastewater (DW) collected from a local sewage well was filtrated by a 400-mesh sieve to remove particles that might block the interspace of electrodes. COD of the filtrated DW was detected as $309 \pm 18 \mathrm{mg} \mathrm{l}^{-1}$ in all experiment, and other key factors of the DW are listed in SI, Table S1. DW was then amended with AO7 (200 $\left.\mathrm{mg} \mathrm{l}^{-1}\right)$ as the influent of one reactor $\left(R_{D W}\right)$. As the controls, the other two reactors $\left(R_{A c}\right.$ and $\left.R_{G l u}\right)$ were fed with the synthetic wastewater with acetate and glucose as the electron donor source, respectively, which contributed the same COD as that in DW. Besides the electron donor sources, the synthetic wastewater was composed of AO7 $\left(200 \mathrm{mg} \mathrm{l}^{-1}\right)$ and other minerals as reported previously (Cheng et al., 2015). 
The performances of three reactors were evaluated under various hydraulic retention times (HRTs), concentrations of electron donor source and buffer capacities of the wastewater, which are summarized as in Table 1. In the Stage 1, the influents of all reactors were buffered with $50 \mathrm{mM}$ phosphate buffer solution (PBS, $\mathrm{pH} \sim 7.2$ ). The concentration of electron donor source was set at $\sim 300 \mathrm{mg} \mathrm{COD} \mathrm{l}^{-1}$. HRTs were fixed at $24 \mathrm{~h}, 12 \mathrm{~h}, 8 \mathrm{~h}$ and $6 \mathrm{~h}$, respectively. In the Stage 2 , the influents were buffered with PBS as well and fed into the reactors with a constant HRT of $6 \mathrm{~h}$. The concentrations of electron donor source were varied at 240, 180, 120 and $80 \mathrm{mg} \mathrm{l}^{-1}$. In the Stage 3, HRT and the concentration of electron donor source of the influents were respectively constant at $6 \mathrm{~h}$ and $300 \mathrm{mg} \mathrm{l}^{-1}$. Effect of PBS on the AO7 decolorization was conducted by operating reactor with $50 \mathrm{mM}$ and without PBS, another experiment was set to distinguish the effect of buffer capacity and conductivity by replacing the PBS with sodium chloride $(\mathrm{NaCl})$, in which the dosing of $\mathrm{NaCl}$ provided the conductivity equal to $50 \mathrm{mM}$ PBS. All of the experiments mentioned above were carried out at ambient temperature $\left(23 \pm 2{ }^{\circ} \mathrm{C}\right)$. For each condition, the reactors were operated for at least 12 HRTs. Data analysis was based on at least 5 samples from different HRTs in each steady state.

\subsection{Analytical methods and calculations}

Liquid samples taken from reactors were immediately filtered through the $0.45 \mu \mathrm{m}$ filters (Tianjin Jinteng Experiment Equipment Co., Ltd., China). AO7 concentration was quantified by a UV-Vis spectrophotometer (UV-1800, Shanghai Meipuda instrument Co., Ltd., China) at a wavelength of $484 \mathrm{~nm}$ (Mu et al., 2009a). SA was measured by a high performance liquid chromatography (HPLC, e2695, Waters Co., U.S.) equipped with a UV-Vis detector (model 2489, Waters Co., U.S.) and a C18 column ( $5 \mu \mathrm{m}$; $4.6 \mathrm{~mm} \times 250 \mathrm{~mm}$, Symmetry, Waters Co., Ltd., U.S.). To prevent the auto-oxidation of the products from AO7 reduction, $1000 \mathrm{mg} \mathrm{l}^{-1} \mathrm{Na}_{2} \mathrm{SO}_{3}$ solution was added to dilute liquid sample by $1: 1$. Gas composition was analyzed by a gas chromatograph (GC, 7890A, Agilent, Inc., US) equipped with a flame ionization detector (FID) and a thermal conductivity detector (TCD). Chemical oxygen demand (COD) determination by using the $\mathrm{HACH}$ vials. $\mathrm{pH}$ and conductivity were measured with FE20-FiveEasy ${ }^{\mathrm{TM}}$ pH meter (Mettler Toledo, China) and Bante 950 conductivity meter (Bante, China), respectively. Calculations including AO7 decolorization efficiency (DE, \%), decolorization rate (DR, $\mathrm{g} \mathrm{m}^{-3} \mathrm{~d}^{-1}$ ), reductant usage ratio (RUR), reductant supply ratio (RSR) and decolorization product (SA) recovery efficiency ( $\left.\eta_{\mathrm{SA}}, \%\right)$, are shown in SI.

\section{Results and discussion}

\subsection{Decolorization performance with domestic wastewater as electron donor source}

With the decrease of HRT, AO7 loading rates increased from 200 to $800 \mathrm{~g} \mathrm{~m}^{-3} \mathrm{~d}^{-1}$ as shown in Fig. 1. Decolorization efficiencies (DEs) of all three reactors were always over 98\%, resulting in the increase of decolorization rates (DRs) almost linear with the AO7 loading rate $\left(R^{2}>0.998\right)$, and finally reached to the range between

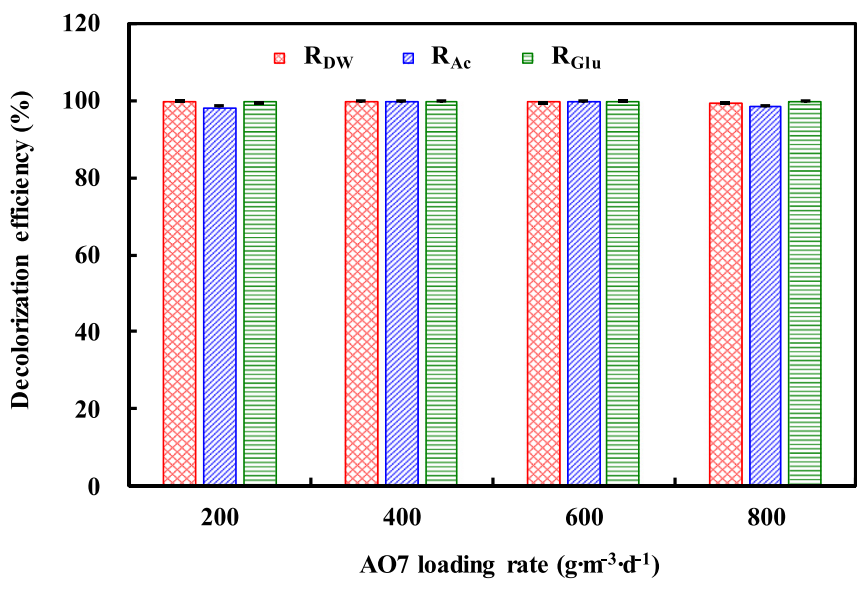

Fig. 1. Effect of electron donor source types (domestic wastewater, NaAc and glucose) on AO7 decolorization efficiency at different loading rates.

$795.05 \pm 60.78$ and $840.96 \pm 49.99 \mathrm{~g} \mathrm{~m}^{-3} \mathrm{~d}^{-1}$ (SI, Fig. S2). In order to confirm the decolorization of $\mathrm{AO7}$ was due to the cleavage of the azo bound, one of the reduced products, sulfanilic acid (SA), was measured in the effluents (Yemashova et al., 2004). As shown in SI, Fig. S3, SA accumulations waved in a narrow range $\left(86-98 \mathrm{mg} \mathrm{l}^{-1}\right)$, accounting to over $87 \%$ of the removed $\mathrm{AO} 7$ in all tested conditions. Current generation was continuously monitored during the decolorization. The currents of the two pairs of electrodes in each reactor were summed and presented in Fig. 2. As the DEs were always closed to $100 \%$ despite of the AO7 loading rates, the current generation was likely controlled by the availability of AO7 as the electron acceptor which showed an increase trend by shorting HRT. In each HRT condition, the types of electron donor source revealed non-significant influence on AO7 decolorization in terms of DR and product accumulation. The decolorization performance of $R_{D W}$ presented here is also comparable to other reported BES fed with simple electron donor sources (NaAc and glucose) at similar azo

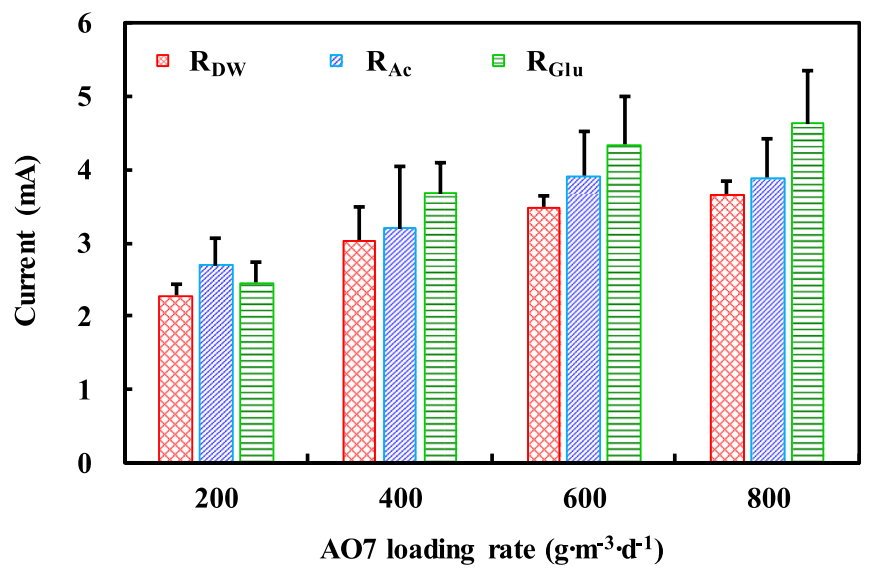

Fig. 2. Currents of domestic wastewater, NaAc and glucose feeding BESs at different loading rates.

Table 1

Operational conditions of hydraulic retention time (HRT), electron donor source concentration and buffer system in this experiment.

\begin{tabular}{|c|c|c|c|}
\hline Stage & HRT (h) & Electron donor source concentration $\left(\mathrm{mg} \mathrm{l}^{-1}\right)$ & Buffer system \\
\hline 1 & $24,12,8,6$ & $\sim 300$ & $50 \mathrm{mM}$ PBS \\
\hline 2 & 6 & $240,180,120,80$ & $50 \mathrm{mM}$ PBS \\
\hline 3 & 6 & $\sim 300$ & 0 PBS \& $\mathrm{NaCl}$ (conductivity $=50 \mathrm{mM}$ PBS) \\
\hline
\end{tabular}


dye loading rate (Cui et al., 2014b). These results clearly indicated that those complicates organics contained in DW were capable of efficiently drive BES to reductively decolorize azo dye as compared to the conventionally used simple organics.

Unlike to the fate of AO7, the changes of COD in reactors fed with different electron donor sources were shown significantly different (Fig. 3). Because the DEs of all reactors were almost the same and the reduced products of $\mathrm{AO} 7$ are stable under anaerobic condition (Yemashova et al., 2004), the variety of COD removal was most likely the result of the different consumption of the electron donor sources. The removed COD in $\mathrm{R}_{\mathrm{DW}}$ was shown as the lowest, which was followed by the $R_{G l u}$ and then by the $R_{A c}$. Although the COD removal in $R_{\mathrm{DW}}$ was not the highest, yet it clearly demonstrated the simultaneous treatment of DW. The RURs of $R_{\mathrm{DW}}$ were estimated from $9.31 \pm 0.86$ to $6.00 \pm 0.94 \mathrm{~mol} \mathrm{COD} \mathrm{mol}^{-1}$ AO7 with the loading rates of $\mathrm{AO} 7$ increasing from 200 to $800 \mathrm{~g} \mathrm{~m}^{-3} \mathrm{~d}^{-1}$. In case of glucose as electron donor source, more reductant was consumed with the RURs various from $10.29 \pm 1.67$ to $11.12 \pm 0.28 \mathrm{~mol} \mathrm{COD} \mathrm{mol}^{-1} \mathrm{AO}$. In $\mathrm{R}_{\mathrm{Ac}}$, the RURs further increased to the range between $16.03 \pm 0.96$ and $11.37 \pm 1.01 \mathrm{~mol} \mathrm{COD} \mathrm{mol}^{-1}$ A07. Theoretically, the reduction of $1 \mathrm{~mol} \mathrm{AO7} \mathrm{requires} 4 \mathrm{~mol}$ electron equivalents, corresponding to the RUR of $1 \mathrm{~mol} \mathrm{COD} \mathrm{mol}{ }^{-1}$ AO7. In despite of the types of electron donor sources, the obtained RURs were higher than this theoretical value, indicating not all of the electrons of the electron donor sources flowed to the AO7 but lost through certain parallel routes, such as the biomass production and the unwanted methanogenesis (van der Zee and Villaverde, 2005).

In order to get insight into the possible electron loss, electron balance was analyzed at the AO7 loading rate of $800 \mathrm{~g} \mathrm{~m}^{-3} \mathrm{~d}^{-1}$ (Table 2). Because of the similar decolorization efficiencies, electrons that flowed to azo dye were close in all reactors. Gas production and the composition analysis were conducted as well. In all reactors, the gas phases were mainly composed by $\mathrm{CH}_{4}$ with infinitesimal $\mathrm{H}_{2}$ and $\mathrm{CO}_{2}$ (two orders of magnitude lower than $\mathrm{CH}_{4}$ ). The rate of $\mathrm{CH}_{4}$ production in $\mathrm{R}_{\mathrm{DW}}$ was $0.29 \pm 0.06 \mathrm{mmol} \mathrm{l}^{-1}$ influent (equal to $2.32 \mathrm{mmol}$ electrons $\mathrm{l}^{-1}$ influent), which was much lower than that in $R_{G l u}\left(0.50 \pm 0.07 \mathrm{mmol} \mathrm{l}^{-1}\right.$ influent or $4.00 \mathrm{mmol}$ electrons $\mathrm{l}^{-1}$ influent) and $\mathrm{R}_{\mathrm{Ac}}\left(1.26 \pm 0.02 \mathrm{mmol} \mathrm{l}^{-1}\right.$ influent or $10.08 \mathrm{mmol}$ electrons $\mathrm{l}^{-1}$ influent). The dissolved $\mathrm{CH}_{4}$ (Table 2) were estimated according to the Henry's law based on the $\mathrm{CH}_{4}$ volume fraction in gas phases (Sander, 2015; Yeo et al., 2015) (details can be found in SI). In addition to methanogenesis, electrons can be also used to supporting bacteria growth. Electrons sunk in assimilation were estimated according to the substrate based yield coefficients and shown in Table 2 (Batstone et al., 2002; Filipe et al. 1998; Ren and Wang, 2004). By comparing the

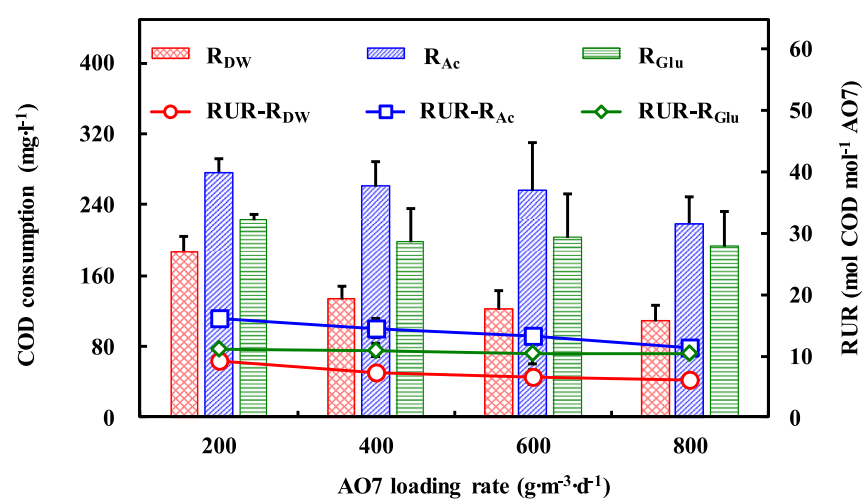

Fig. 3. COD consumptions and reductant usage ratios (RURs) of domestic wastewater, NaAc and glucose feeding BESs at different loading rates.
Table 2

Electron balance analysis in domestic wastewater, NaAc and glucose feeding BESs at AO7 loading rate of $800 \mathrm{~g} \mathrm{~m}^{-3} \mathrm{~d}^{-1}$.

\begin{tabular}{llll}
\hline & $\mathrm{R}_{\mathrm{DW}}$ & $\mathrm{R}_{\mathrm{Ac}}$ & $\mathrm{R}_{\mathrm{Glu}}$ \\
\hline Electron consumption $^{\mathrm{a}}$ & & & \\
$\mathrm{AO}$ decolorization $^{\mathrm{a}}$ & 2.27 & 2.24 & 2.27 \\
$\mathrm{CH}_{4}$ collected in gas phase $^{\mathrm{b}}$ & 2.32 & 10.08 & 4.00 \\
$\mathrm{CH}_{4}$ dissolved in aqueous phase $^{\mathrm{c}}$ & 4.06 & 7.72 & 5.36 \\
Microbial growth $^{\mathrm{d}}$ & 0.06 & 1.37 & 2.41 \\
Electron supply & & & \\
Removed COD $^{\mathrm{e}}$ & 13.61 & 27.31 & 24.12 \\
$\begin{array}{l}\text { Electron recovery efficiency } \\
\eta(\%)\end{array}$ & 64.00 & 78.40 & 58.21 \\
\hline
\end{tabular}

Unit (exclude electron recovery efficiency) is mmol electrons $\mathrm{l}^{-1}$ influent

a $1 \mathrm{~mol} \mathrm{AO7} \mathrm{decolorization} \mathrm{consumed} 4 \mathrm{~mol}$ electrons.

b $1 \mathrm{~mol} \mathrm{CH}_{4}$ contributed 8 mol electrons.

c According to Henry's law as shown in SI (Sander, 2015; Yeo et al., 2015).

d Microbial yield, $\mathrm{Y}_{\mathrm{DW}}=0.0044, \mathrm{Y}_{\mathrm{Ac}}=0.05, \mathrm{Y}_{\mathrm{Glu}}=0.1$, biomass as COD/consumed COD (Batstone et al., 2002; Filipe et al. 1998; Ren and Wang, 2004).

e $1 \mathrm{~mol}$ COD released $4 \mathrm{~mol}$ electrons.

consumed electron equivalents (COD), electrons that sunk in decolorization, methanogenesis and assimilation could account for $78.40 \%, 58.21 \%$ and $64.00 \%$ of those released from COD removal in, $R_{A c}, R_{G l u}$ and $R_{D W}$, respectively. Here, the relative poor electron balance observed in $R_{G l u}$ and $R_{D W}$ is likely because that the fermentation of DW and glucose is not taken into account. As shown in Table $2, \mathrm{R}_{\mathrm{Ac}}$ has the highest $\mathrm{CH}_{4}$ production rate as expected because acetate is one of the few substrates catered to the methanogens (Chen et al., 2011; Khan et al., 2014). Compared to $\mathrm{R}_{\mathrm{DW}}$, the more produced $\mathrm{CH}_{4}$ in $\mathrm{R}_{\mathrm{Ac}}$ could explain over $80 \%$ of its more consumed COD. $\mathrm{R}_{\mathrm{Glu}}$ also produced more $\mathrm{CH}_{4}$ than $\mathrm{R}_{\mathrm{DW}}$. When taking into account its higher biomass yield, these two aspects could explain around half of the more consumed COD. These results clearly indicated that the greater RURs in $R_{A c}$ and $R_{G l u}$ compared to $\mathrm{R}_{\mathrm{DW}}$ were attributed to more electrons lost into the side reactions.

\subsection{Decolorization performance with decreasing electron donor source concentrations}

DEs kept above 90\% regardless of the types of electron donor sources till the concentration (as COD) dropped to about $120 \mathrm{mg} \mathrm{l}^{-1}$ (Fig. 4). At the lower COD of the electron donor sources $\left(80 \mathrm{mg} \mathrm{l}^{-1}\right)$, DE of $R_{D W}$ was almost not change, while $9.33 \%$ and $19.92 \%$ decrease of DEs were observed in $R_{G l u}$ and $R_{A c}$, respectively. Similar to that

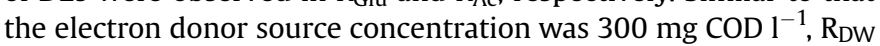

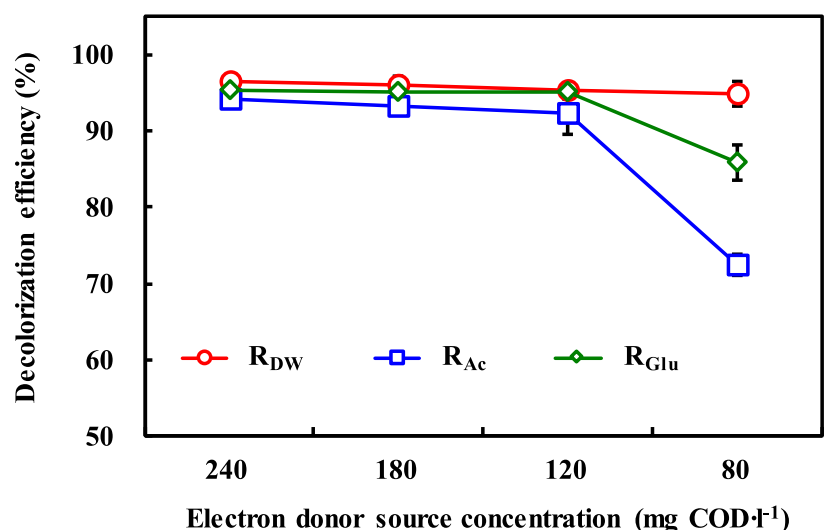

Fig. 4. Effect of domestic wastewater, NaAc and glucose concentrations on AO7 decolorization efficiency at AO7 loading rate of $800 \mathrm{~g} \mathrm{~m}^{-3} \mathrm{~d}^{-1}$. 
consumed less COD compared to $\mathrm{R}_{\mathrm{Glu}}$ and $\mathrm{R}_{\mathrm{Ac}}$ in case of decreasing the dosage of electron donor source (Fig. 5). The estimated RURs of all three reactors were declined rapidly by reducing the electron donor source concentration from 240 to $80 \mathrm{mg} \mathrm{COD} \cdot \mathrm{l}^{-1}$ and then were respectively stable around $3.4,5.6$ and $5.8 \mathrm{~mol} \mathrm{COD} \mathrm{mol}^{-1}$ $A 07$ for $R_{D W}, R_{G l u}$ and $R_{A c}$, which suggested the minimum required electron equivalents for AO7 decolorization under different electron donor source conditions. Compared to the reductants supply ratios (RSRs) that were theoretically calculated according to the concentrations of AO7 and the electron donor sources, RURs of all reactors were lower than the corresponding RSRs when the concentration of electron donor sources was set at or higher than $120 \mathrm{mg} \mathrm{l}^{-1}$, indicating the provided electron equivalents was more than that required. When the concentration of electron donor source was further reduced to $80 \mathrm{mg} \mathrm{l}^{-1}$, RSR decreased to $4.4 \mathrm{~mol} \mathrm{COD} \mathrm{m^{-1 }}$ AO7 which became lower than the RURs obtained in $R_{G l u}$ and $R_{A c}$ but was still higher than that in $R_{D W}$. This result clearly indicated that the decline of $D E s$ in $R_{G l u}$ and $R_{A c}$ was due to the insufficiency of electron donor sources.

\subsection{Effect of buffer systems on the decolorization performance}

PBS is the commonly used buffer system in bioelectrochemical studies, which could provide a desirable conductivity and buffer capacity for the systems. However, any external additions of buffer salts would increase the operation cost and may be even worse by introducing secondary pollutions. Based on this concern, all of the reactors were further tested by feeding synthetic wastewater without PBS. As shown in Fig. 6A, DE of $R_{D W}$ was slight decreased by $5.94 \%$ to $93.52 \pm 0.74 \%$, while $D E$ of $R_{A c}$ and $R_{G l u}$ were dramatically deteriorated to around $80 \%$.

In absence of PBS, the effluent of $\mathrm{R}_{\mathrm{Ac}}$ basified with $\mathrm{pH}$ increasing to $7.83 \pm 0.09$, which was likely the result of the consumption of $\mathrm{H}^{+}$ in methanogenesis that cannot be supplemented through the buffer effect (Fig. 6B). Similarly, when reactor was fed by glucose, fatty acids can be produced by fermentation and therefore caused the decrease of effluent $\mathrm{pH}$ to $5.68 \pm 0.13$. Unlike to $\mathrm{R}_{\mathrm{AC}}$ and $\mathrm{R}_{\mathrm{Glu}}$, effluent $\mathrm{pH}$ of $\mathrm{R}_{\mathrm{DW}}$ remained stable without adding buffer salts. This $\mathrm{pH}$ stability was found to attribute to the natural buffer capacity of DW. As shown in SI, Fig. S4, the buffer capacity was defined as the $\mathrm{pH}$ change along with adding $1 \mathrm{~mL} 0.1 \mathrm{M} \mathrm{HCl} / \mathrm{NaOH}$ into $100 \mathrm{~mL}$ synthetic wastewater. The $\mathrm{pH}$ of $\mathrm{DW}$ composited influent only changed $1.04 / 0.91$ units with $\mathrm{HCl} / \mathrm{NaOH}$ adding, which was much lower than that of the acetate (2.00/3.21 units)

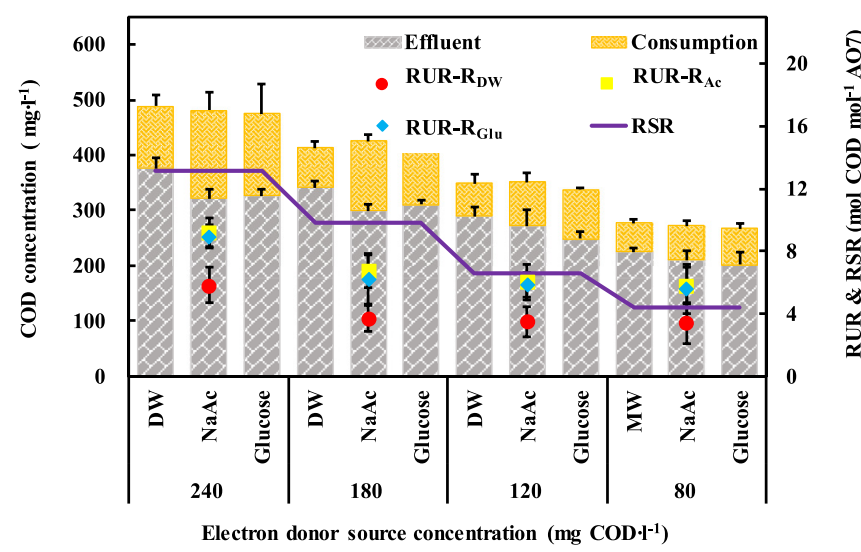

Fig. 5. COD variations, reductant usage ratios (RURs) and reductants supply ratios (RSRs) at different concentration of domestic wastewater, NaAc and glucose at AO7 loading rate of $800 \mathrm{~g} \mathrm{~m}^{-3} \mathrm{~d}^{-1}$. and glucose composited (3.82/3.13 units) ones.

In addition to the alteration of $\mathrm{pH}$, the conductivities of influents decreased a lot due to the absence of PBS (Fig. 6C). Nevertheless, the conductivity of the influent with DW as electron donor source was 1.4 and 2.6 times higher than that with acetate and glucose, respectively. The higher conductivity in DW here is likely due to its more complicate composition compared to the defined synthetic wastewater, especially those inorganic slats and VFAs in DW could considerably contribute the conductivity (Cook et al., 2015; Scott et al., 2007).

In order to distinguish the effects of $\mathrm{pH}$ and conductivity on the decolorization performances, additional experiment was conducted by replacing PBS using $\mathrm{NaCl}$ which provided the same conductivity as $50 \mathrm{mM}$ PBS. As shown in Fig. 6B, pHs in all effluents were almost not change after replacing by $\mathrm{NaCl}$, confirming the buffer capacities was not improved. Over $90 \%$ recoveries of decolorization efficiencies as well as the currents (Fig. 6D) were observed in $R_{D W}$ and $\mathrm{R}_{\mathrm{Ac}}$, clear indicating their decolorization deterioration in absence of external salts owed to the limited bioelectrochemical process because of the low conductivity other than the $\mathrm{pH}$ change. In $\mathrm{R}_{\mathrm{Glu}}$, although the conductivity was almost fully recovered after adding $\mathrm{NaCl}$, the corresponding $\mathrm{DE}$ and current were just recovered by $86 \%$ and $77 \%$, respectively. This result suggested the limitation of bioelectrochemical decolorization in $\mathrm{R}_{\mathrm{Glu}}$ fed with PBS free influent attributed both to the variation of conductivity and $\mathrm{pH}$. Because of the natural higher conductivity and buffer capacity of DW, the current drop of $R_{D W}$ was lower than that of $R_{A c}$ and $R_{G l u}$ under external buffer slats free condition, and consequently explained the corresponding higher decolorization efficiency.

\subsection{Implications}

Decolorization of textile wastewater was suggested to be limited owing to the lack of efficient electron donor (Şen and Demirer, 2003). Compared to external adding electron donors, such as glucose and VFAs, DW is obviously more cost-effective. However, RURs in traditional anaerobic decolorization process are usually at the value from tens to hundreds, while the COD as electron donor source in DW is low. For a typical azo dye wastewater treatment plant, the scale is usually at 10,000 tons per day with the concentration of azo compound at $1 \mathrm{mM}$. To meet the average RUR ( $50 \mathrm{~mol} \mathrm{COD} \mathrm{mol}^{-1}$ azo dye) in conventional anaerobic process, the required DW (COD is assumed as $300 \mathrm{mg} \mathrm{l}^{-1}$ ) would be 5.3 times in amount higher than the textile wastewater. According to the typical personal wastewater discharge constant $\left(180 \mathrm{l} \mathrm{d}^{-1}\right)$, the required DW equals to that contributed by a population of 294,000 . This huge requirement of DW reduces the accessibility of DW because of the population limitation and the high cost of DW transportation. In case of BES, the RUR for decolorization has been reported to be much lower than conventional anaerobic process when using simple organics as electron donor (as shown in SI, Table S2). Here, we further demonstrated this excellent property of BES remained in DW as electron donor source. Based on the assumption as mentioned above, the mixture ratio of DW and textile wastewater can be as low as to 0.36 according to the experimental data in this work (3.4 mol COD mol ${ }^{-1}$ azo dye), which is 14.7 times lower than that calculated according to conventional anaerobic process and therefore considerably facilitate DW as the electron donor source. In this case, DW capacity of at least 3600 tons per day can be simultaneously treated by serving as electron donor source for driving azo dye wastewater decolorization.

In practical, the concentration of azo dyes in textile waster and COD in DW could be varied and therefore may lead a loading shock to the BES. In the present work, high DE remained even the RSR decreased to $4.4 \mathrm{~mol} \mathrm{COD} \mathrm{mol}^{-1}$ azo dye in $\mathrm{R}_{\mathrm{DW}}$, which provide an 

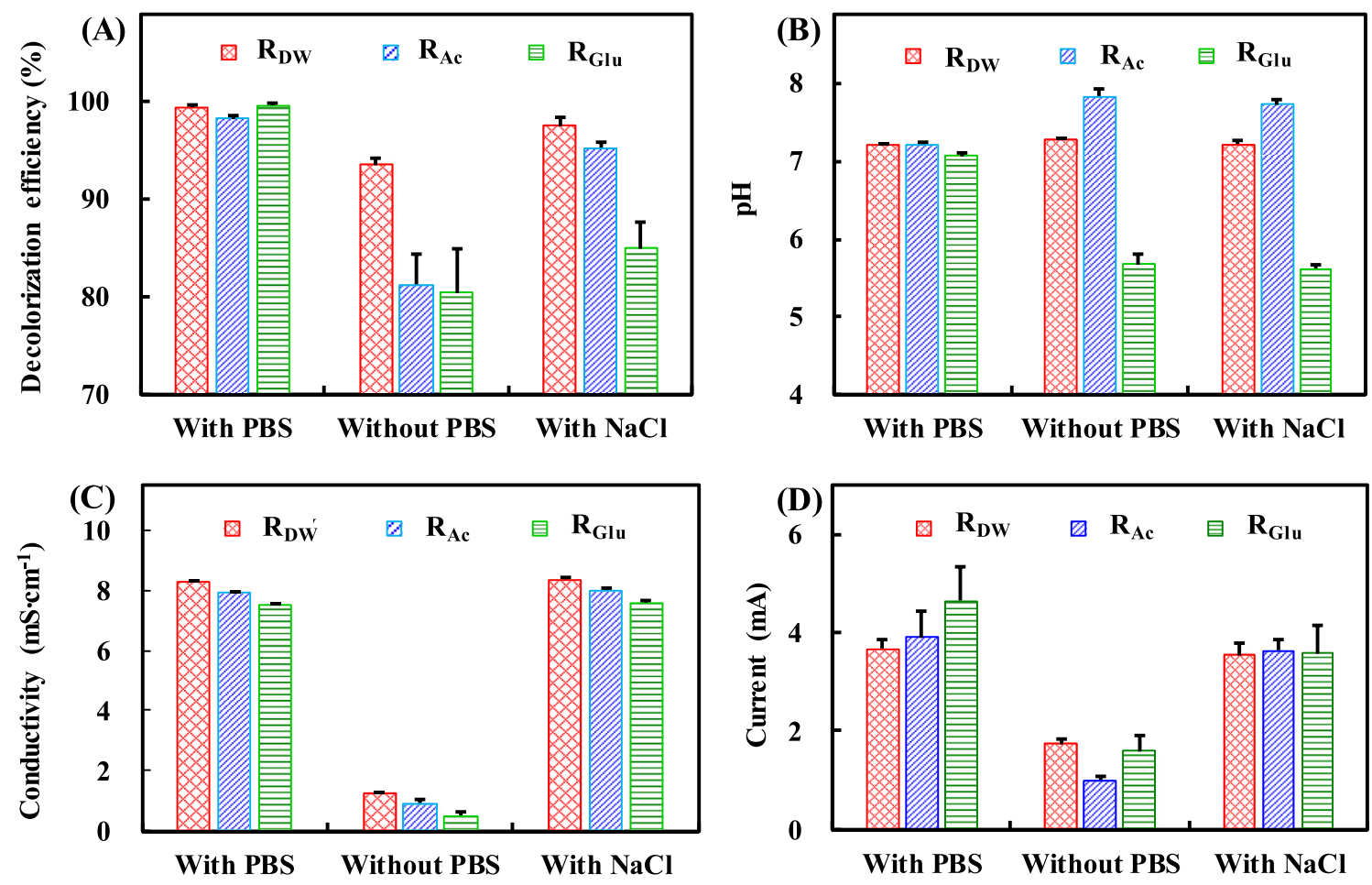

Fig. 6. Effect of buffer systems on: (A) Decolorization efficiency; (B) $\mathrm{pH}$; (C) Influent conductivity; (D) Current at AO7 loading rate of $800 \mathrm{~g}^{-3} \mathrm{~d}^{-1}$.

endurable bottom line of RSR for operating BES efficiently. This bottom line can be used as an alert in case of loading shock or guide the mixing ratio of DW and azo dye containing wastewater into an acceptable range.

In regard to a BES, conductivity of the wastewater is often considered to significantly influence the performance (Nam et al., 2010). Unlike to adding solid electron donors, DW as electron donor source would dilute the original azo dye containing wastewater and consequently can decrease the conductivity in mixed wastewater, which could ostensibly make the DW as electrode donor source doubtful. In the present work, we did observe the deterioration of decolorization performance under PBS free condition. However, as DW naturally has certain conductivity, the decolorization efficiency just decreased a little and remained over $90 \%$. This result further strengths the feasibility of using DW to drive the azo dye decolorization in BES.

\section{Conclusion}

This work demonstrated that domestic wastewater (DW) could efficiently drive azo dye decolorization in BES. Compared to the conventional added sodium acetate and glucose, DW as electron donor source showed comparable decolorization performance under high RSR condition yet is obviously much more cost-effective and could gain side benefit of the simultaneous treatment of DW. In addition, BES fed with DW consumed less reduced equivalent, which can favor the decolorization under low RSR condition. Moreover, DW can also provide some buffer capacity and conductivity, enabling less deteriorated when fully removing the external buffer slats. These findings comprehensively revealed the feasibility and superiority of DW as an electron donor source in BES and illuminate the practical potential of this technology in wastewater treatment.

\section{Acknowledgement}

This research was supported by the National Nature Science Foundation for Distinguished Young Scholars (Grant No. 51225802), the National Nature Science Foundation of China (Grant No. 21577162, 21407164), the China Postdoctoral Science Foundation (Grant No. 2015M580140, No. 2016T90142), the Ministry of Environmental Protection of the People's Republic of China (Major Science and Technology Program for Water Pollution Control and Treatment) (Grant No. 2014ZX07204-005), the "Hundred Talents Program" of the Chinese Academy of Sciences (Grant No. 29BR2013001) and Science and Technology Service Network Initiative Project of Chinese Academy of Sciences (Grant No. KFJEW-STS-102).

\section{Appendix A. Supplementary data}

Supplementary data related to this article can be found at http:// dx.doi.org/10.1016/j.watres.2016.09.027.

\section{References}

Batstone, D.J., Angelidaki, I., Kalyuzhnyi, S.V., Pavlostathis, S.G., Rozzi, A., Siegrist, H., Vavilin, V.A., 2002. Anaerobic Digestion Model No. 1. IWA Publishing.

Cardenas-Robles, A., Martinez, E., Rendon-Alcantar, I., Frontana, C., GonzalezGutierrez, L., 2013. Development of an activated carbon-packed microbial bioelectrochemical system for azo dye degradation. Bioresour. Technol. 127, 37-43.

Chen, Z.B., Cui, M.H., Ren, N.Q., Chen, Z.Q. Wang, H.C., Nie, S.K., 2011. Improving the simultaneous removal efficiency of COD and color in a combined HABMRCFASR system based MPDW. Part 1: optimization of operational parameters for HABMR by using response surface methodology. Bioresour. Technol. 102 (19), 8839-8847.

Cheng, H.Y., Liang, B., Mu, Y., Cui, M.H., Li, K., Wu, W.M., Wang, A.J., 2015. Stimulation of oxygen to bioanode for energy recovery from recalcitrant organic matter aniline in microbial fuel cells (MFCs). Water Res. 81, 72-83.

Cook, N.A., Krometis, L.H., Sarver, E.A., Huang, J., 2015. Inorganic constituents of conductivity in five central Appalachian watersheds with mixed source-driven pollutants. Ecol. Eng. 82, 175-183. 
Cui, D., Guo, Y.-Q., Lee, H.-S., Cheng, H.-Y., Liang, B., Kong, F.-Y., Wang, Y.-Z., Huang, L.-P., Xu, M.-Y., Wang, A.-J., 2014a. Efficient azo dye removal in bioelectrochemical system and post-aerobic bioreactor: optimization and characterization. Chem. Eng. J. 243, 355-363.

Cui, D., Guo, Y.Q., Lee, H.S., Wu, W.M., Liang, B., Wang, A.J., Cheng, H.Y., 2014b. Enhanced decolorization of azo dye in a small pilot-scale anaerobic baffled reactor coupled with biocatalyzed electrolysis system (ABR-BES): a design suitable for scaling-up. Bioresour. Technol. 163C, 254-261.

Cui, M.-H., Cui, D., Lee, H.-S., Liang, B., Wang, A.-J., Cheng, H.-Y., 2016a. Effect of electrode position on azo dye removal in an up-flow hybrid anaerobic digestion reactor with built-in bioelectrochemical system. Sci. Rep. 6, 25223.

Cui, M.-H., Cui, D., Liang, B., Sangeetha, T., Wang, A.-J., Cheng, H.-Y., 2016b. Decolorization enhancement by optimizing azo dye loading rate in an anaerobic reactor. RSC Adv. 6 (55), 49995-50001.

Cui, M.H., Cui, D., Gao, L., Cheng, H.Y., Wang, A.J., 2016c. Efficient azo dye decolorization in a continuous stirred tank reactor (CSTR) with built-in bioelectrochemical system. Bioresour. Technol. 218, 1307-1311.

Filipe, C.D.M., Grady, C.P.L., Grady Jr., 1998. Biological Wastewater Treatment, second ed. Crc Press. Revised and Expanded.

Ganesh, R., Boardman, G.D., Michelsen, D., 1994. Fate of azo dyes in sludges. Water Res. 28 (6), 1367-1376.

Gregoire, K.P., Becker, J.G., 2012. Design and characterization of a microbial fuel cell for the conversion of a lignocellulosic crop residue to electricity. Bioresour. Technol. 119, 208-215.

Heidrich, E.S., Edwards, S.R., Dolfing, J., Cotterill, S.E., Curtis, T.P., 2014. Performance of a pilot scale microbial electrolysis cell fed on domestic wastewater at ambient temperatures for a 12month period. Bioresour. Technol. 173C, 87-95.

Huang, L., Jiang, L., Wang, Q., Quan, X., Yang, J., Chen, L., 2014. Cobalt recovery with simultaneous methane and acetate production in biocathode microbial electrolysis cells. Chem. Eng. J. 253 (3), 281-290.

Khan, M.Z., Singh, S., Sreekrishnan, T.R., Ahammad, S.Z., 2014. Feasibility study on anaerobic biodegradation of azo dye reactive orange 16. RSC Adv. 4 (87), 46851-46859.

Kim, K.Y. Yang W., Logan, B.E., 2015. Impact of electrode configurations on retention time and domestic wastewater treatment efficiency using microbial fuel cells. Water Res. 80, 41-46.

Kong, D., Liang, B., Yun, H., Cheng, H., Ma, J., Cui, M., Wang, A., Ren, N., 2015. Cathodic degradation of antibiotics: characterization and pathway analysis. Water Res.

Liang, B., Cheng, H.Y., Kong, D.Y., Gao, S.H., Sun, F., Cui, D., Kong, F.Y., Zhou, A.J. Liu, W.Z., Ren, N.Q., Wu, W.M., Wang, A.J., Lee, D.J., 2013. Accelerated reduction of chlorinated nitroaromatic antibiotic chloramphenicol by biocathode.
Environ. Sci. Technol. 47 (10), 5353-5361

Luo, H., Liu, G., Zhang, R., Bai, Y., Fu, S., Hou, Y., 2014. Heavy metal recovery combined with $\mathrm{H}(2)$ production from artificial acid mine drainage using the microbial electrolysis cell. J. Hazard. Mater. 270, 153-159.

Mu, Y., Rabaey, K., Rozendal, R.A., Yuan, Z.G., Keller, J., 2009a. Decolorization of azo dyes in bioelectrochemical systems. Environ. Sci. Technol. 43 (13), 5137-5143.

Mu, Y., Rozendal, R.A., Rabaey, K., Keller, J., 2009b. Nitrobenzene removal in bioelectrochemical systems. Environ. Sci. Technol. 43 (22), 8690-8695.

Nam, J.Y. Kim, H.W. Lim, K.H., Shin, H.S., Logan, B.E., 2010. Variation of powe generation at different buffer types and conductivities in single chamber microbial fuel cells. Biosens. Bioelectron. 25 (5), 1155-1159.

Pous, N., Koch, C., Colprim, J., Puig, S., Harnisch, F., 2014. Extracellular electron transfer of biocathodes: revealing the potentials for nitrate and nitrite reduction of denitrifying microbiomes dominated by Thiobacillus sp. Electrochem. Commun. 49, 93-97.

Ren, N.Q., Wang, A.J., 2004. Anaerobic Biological Technology Principle and Application (In Chinese). Chemical Industry Press.

Sander, R., 2015. Compilation of Henry's law constants (version 4.0) for water as solvent. Atmos. Chem. Phys. 15 (8), 4399-4981.

Scott, K., Rimbu, G.A., Katuri, K.P., Prasad, K.K., Head, I.M., 2007. Application of modified carbon anodes in microbial fuel cells. Process Saf. Environ. Prot. 85 (5), 481-488.

Selvam, K., Swaminathan, K., Chae, K.S., 2003. Microbial decolorization of azo dyes and dye industry effluent by Fomes lividus. World J. Microbiol. Biotechnol. 19 (6), 591-593.

Sen, S., Demirer, G.N., 2003. Anaerobic treatment of real textile wastewater with a fluidized bed reactor. Water Res. 37 (8), 1868-1878.

van der Zee, F.P., Villaverde, S., 2005. Combined anaerobic-aerobic treatment of azo dyes-a short review of bioreactor studies. Water Res. 39 (8), 1425-1440.

Wang, A.J., Cheng, H.Y., Liang, B., Ren, N.Q., Cui, D., Lin, N., Kim, B.H., Rabaey, K., 2011 Efficient reduction of nitrobenzene to aniline with a biocatalyzed cathode. Environ. Sci. Technol. 45 (23), 10186-10193.

Wang, L., Liu, W., Kang, L., Yang, C., Zhou, A., Wang, A., 2014. Enhanced biohydrogen production from waste activated sludge in combined strategy of chemical pretreatment and microbial electrolysis. Int. J. Hydrogen Energy 39 (23) 11913-11919.

Yemashova, N., Telegina, A., Kotova, I., Netrusov, A., Kalyuzhnyi, S., 2004. Decolorization and partial degradation of selected azo dyes by methanogenic sludge. Appl. Biochem. Biotechnol. 119 (1), 31-40.

Yeo, H., An, J., Reid, R., Rittmann, B.E., Lee, H.S., 2015. Contribution of liquid/gas mass-transfer limitations to dissolved methane oversaturation in anaerobic treatment of dilute wastewater. Environ. Sci. Technol. 49 (17), 10366-10372. 